\title{
The Nature of Nurturing Care for Pediatricians
}

\author{
Sharmila B MukherJee, ${ }^{1}$ Rajesh Mehta ${ }^{2}$ \\ ${ }^{1}$ Lady Hardinge Medical College \& associated Kalawati Saran Children's Hospital, New Delhi; \\ ${ }^{2}$ Division of Newborn, Child and Adolescent Health, World Health Organization - \\ South East Asia Regional Office,NewDelhi.*theshormi@gmail.com \\ Correspondence to: Dr Sharmila B Mukherjee, Department of Pediatrics, Lady Hardinge Medical College, New Delhi.
}

$\mathrm{T}$ he child health programs in the eighties that were intended for under-fives, focused on decreasing mortality and morbidity from infectious diseases, as per the prevailing epidemiology, health needs and priorities of those times. Once these started showing dividends, the focus gradually started to shift from survival to healthy survival. Soon after, early childhood development (ECD) started getting attention, and with it the debate on which had more significant impact on the child, 'nature' or 'nurture'. By the turn of the century, the association between ECD and the quality of maternal health, pregnancy, and the initial years of a child's life was recognized. It became accepted that 'nature' and 'nurture' are inexorably inter-related and cannot be demarcated as separate influencers.

The experiences that a young child is exposed affect future health, wellbeing and adult productivity. The first Lancet series on child development in 2007 [1] had a major impact in the scientific world when it revealed the huge magnitude of children not reaching their expected developmental potential, especially in low- and middleincome countries (LMICs). Since then, two other Lancet series, in 2011 and 2016 [2,3], have further broadened the understanding of ECD by collating scientific evidence related to pertinent dimensions; factors significantly influencing ECD, the social and financial implications of neglecting ECD, and the transgenerational effect of adverse experiences and chronic stress on ECD. It has been highlighted that ECD can be enhanced even in presence of social adversities by basic early interventions. This has been recognized as the greatest equalizer by the commission on social determinants of health [4]. Good health, adequate nutrition, responsive caregiving, safety and security, and providing opportunities for early learning are collectively referred to as the Nurturing Care Framework for ECD (NCF). This framework involves multiple sectors and stakeholders; the individual, the family, the community, the government, and international bodies. Pediatricians can play a unique role in promoting $\mathrm{NC}$ for $\mathrm{ECD}$, as they are usually the first point of contact for young children and their families. They can easily offer additional preventive and promotive healthcare, in addition to existing services.

The articles in this supplementary issue cover various aspects of NC for ECD. We hope these will help our readers broaden their professional horizons by under-standing the concept and importance of close collaboration with primary caregivers. We begin with papers high-lighting the global and national systems that support NC for ECD. It is very important that we all be aware of India's existing ECD-directed policies and programs, and the status of the trajectory with which we are heading towards the 2030 Sustainable Developmental Goals (SDGs). Families benefit when they are empowered with information on comprehensive healthcare for children provided by medical professionals, who can also take up advocacy when the needed. Society benefits when stakeholders across multiple sectors work synergistically i.e., when the private sector, non-government organizations (NGOs) and government form public-private partnerships. This can result in circumventing challenges and obstacles which may not get addressed when working in isolation. The nation benefits when these endeavors enable future generations including the marginalized sections, to achieve their maximum developmental potential due to this 'whole of society' approach.

We have included papers that focus on targeted nurturing care (for populations at high risk for developmental delay). These encompass strategies for the delivery of facility based developmentally supportive care to sick neonates by involving caregivers, who continue with the same at home. The article on the psychosocial stimulation of children with severe acute malnutrition [5] helps us realize the glaring lacunae that still exist, even though we generally assume ourselves to be competent in delivering the ten steps of nutritional rehabilitation. The conceptual shift of focus from developmental screening and surveillance by professionals, to the delivery of developmentally promotive and supportive home-based interventions by parents to their children has been discussed. This is substantiated by papers 
[6] that present real time experiential lessons derived from the ECD directed community-based parental programs that employed responsive caregiving and providing opportunities for early learning, besides existing health and nutrition services. The results that led to scaling up [6], are promising and strengthen the hope that we can all make a difference by incorporating $\mathrm{NC}$ for ECD in our own office practice (one of the goals of the IAP Presidential action plan for ECD). Mukherjee and Srivastava [7] describe the overlooked aspect of 'safety and security' and suggest ways by which pediatricians can help families keep their children safe.

Thus, the papers deal with universal services for all children, targeted interventions for those at high risk, and indicated services for children with special needs. The reader will get acquainted with large-scale government endeavors like Rashtriya Bal Suraksha Karyakram, as well as localized delivery of services on a much smaller scale by dedicated NGOs. This highlights the fact that everyone can contribute their bit if they desire to. One article [8] showcases the innovative use of mobile phones to promote ECD. This is particularly of relevance during the current pandemic, when establishing face-to-face contact has become challenging. Last but not the least, a group of domain experts deliberate upon the mechanisms by which NC-ECD should and can be included in medical undergraduate and postgraduate training [9]. This will enable the creation of a workforce of doctors trained in and committed to ECD from the onset.

As you go through the issue, you will realize that though the single aim of NCF is to achieve optimal ECD, it is nonetheless multi-dimensional by necessity. The childcare practices covered in each individual component of NCF may appear simple, yet the process of getting parents to change their understanding and behavior, and adopt these into their usual child rearing practices depends on continuous support from several entities. As pediatricians we owe it to ourselves and the children we serve, to incorporate NC for ECD in our daily practice. This will not only benefit the family, but also contribute to national development and our collective progress to achieve the SDGs targets before 2030.

Funding: None; Competing interests: Note stated.

\section{REFERENCES}

1. Grantham-McGregor S, Cheung YB, Cueto S, et al. Developmental potential in the first 5 years for children in developing countries. Lancet. 2007;369:60-70.

2. Walker SP, Wachs TD, Grantham-McGregor S, et al. Inequality in early childhood: risk and protective factors for early childhood development. Lancet. 2011:378; 1325-38.

3. Black MM, Walker SP, Fernald LCH, et al. Early childhood development coming of age: science through the life course, Lancet. 2017;389:77-90.

4. Irwin A, Valentine $\mathrm{N}$, Brown $\mathrm{C}$, et al. The Commission on social determinants of health: Tackling the social roots of health inequities. PLoS Med. 2006;3:e106.

5. Kumar P, Rohatgi S, Singh P, Daniel A. Strengthening psychosocial stimulation in the management of children with severe acute malnutrition: Experience from a nutritional rehabilitation centre. Indian Pediatr 2021:58. (Suppl.1):545-48.

6. Gupta S, Raut A, Kothekar P, et al. Nurturing care interventions for realizing the development potential of every child: from pilot to scale up. Indian Pediatr. 2021;58 (Suppl.1):S49-55.

7. Mukherjee SB, Srivastava RN. Role of pediatricians in early childhood nurturing care related to safety and security. Indian Pediatr. 2021;58 (Suppl.1):S585-89.

8. Kumar V, Mohanty P, Sharma M. Promotion of early childhood development using mHealth: Learnings from an implementation experience in Haryana. Indian Pediatr. 2021;58 (Suppl.1):S40-45.

9. Singh T, Sharma M, Gupta P. Incorporating nurturing care for early childhood development in pre-service and in-service training. Indian Pediatr. 2021;58 (Suppl.1):S90-93. 